\title{
Generation and Composition of Medical Waste Derived From Histopathology Laboratories
}

\author{
Katerina Kalogiannidou ${ }^{1}$, Dimitrios Komilis ${ }^{2}$ \\ ${ }^{1}$ Environmental Engineering and Science, Democritus University of Thrace \\ Xanthi, Greece \\ kalogiannidou91@gmail.com \\ ${ }^{2}$ Solid Waste Management, Department of Environmental Engineering, Democritus University of Thrace \\ Xanthi, Greece \\ dkomilis@env.duth.gr
}

\begin{abstract}
The aim of this work was to record the quantities and composition of medical waste (MW) generated by public and private histopathological laboratories (HISTOLB) and to provide a design waste generation coefficient (e.g. g/examinee) characteristic to those laboratories. This can be a useful coefficient when designing medical waste treatment facilities.The study was conducted on three public and four private HISTOLB in the city of Thessaloniki (Greece) for a period of 5 months. One sampling week was selected randomly per month.During the study period, the examinees per week were 108 and 90 in the public and private HISTOLB, respectively.According to the results, 57\% of the total MW generated in both the public and private laboratories were toxicwaste (TXW), namely the liquid formaldehyde that is used to preserve the tissue. The mixed hazardous waste (MHW) comprised28\% and 24\%, respectively, of the total MW, in the public and private facilities, respectively. The infectious waste constitutedaround $15 \%$ of the total MW generated in both types of facilities. Urban type waste wasalways less than $4 \%$ by weight. The total MW generated in the public and private laboratories were $281 \pm 121$ and $214 \pm 115 \mathrm{~g} /$ examinee, respectively. No statistical differences were found between the MW generation rates of the public and private laboratories. However, a large variance in the MW generation rates among individual laboratories that belonged to the same categorywas observed. The dominant fraction of the infectious waste was the plastic containers that contained the tissue samples, being around $75 \%$ of the total infectious waste, followed by the latex gloves (around $17 \%$ of the infectious waste).
\end{abstract}

Keywords: Medical Waste, Health-Care Waste, Histopathology, Infectious, Toxic, Hazardous.

\section{Introduction}

Medical waste (MW) or health-care waste is the solidand liquid waste generated from healthcare facilities. Medical waste includes a wide range of materials such as bandages, needles, body parts, blood, sample containers, chemical solutions, pharmaceutical products, medical devices and radioactive materials [1]. According to the World Health Organization [1],approximately $85 \%$ of the MW are non-hazardous waste; therefore, only $15 \%$ have hazardous properties, namely being infectious, toxic and radioactive. However, this is a rough estimate and there have been several studies over the past decade to further investigate the generation rates and composition of MW from various types of healthcare facilities and activities.[2], [3], [4], [5]

The common sources of MW are the materials used to examine and treat examinees/patients as well as the waste produced from the medical staff.The types of waste produced by a health-care facility highly depend on local legislation and on the separation of MW that takes place within the facility. [6]Additional factors that affect MW generation are the type of the health-care facility, its status (public or private sector), and the percentage of consumable materials used in healthcare activities. [7].

\subsection{Categorization of Medical Waste}

The most common categorization of MW around the world is into the hazardous and non-hazardous waste fractions. In addition, infectious waste and/or sharps can be separate categoriestoo. One of the most thorough categorizations of MW is described in the Greek legislation. In Greece, MW are categorized into: i) urban type nonhazardous medical waste and ii) hazardous medical waste. The latter category is further grouped into a) infectious waste (INFW), b) infectious and toxic (mixed hazardous) waste (MXW) and the c) solely toxic waste (TXW). Special waste (e.g. radioactive waste, batteries) is another separate category of the hazardous waste fraction. 


\subsection{Scope of the Work}

No information appears to exist in the international literature on the generation rates and composition of MW generated by HISTOLBs. Thus, the objective of this research work was to calculate the quantities and composition of waste generated by such laboratories after performing on site measurements. The ultimate goal of the workwas to develop a waste coefficient expressed in mass ( $\mathrm{g}$ ) of waste per examineefor HISTOLBs in both the public and private sector. The composition of MW was assessed too by grouping MW according to the Greek legislation, namely into urban type, infectious waste, mixed hazardous waste and solely toxic waste.

\subsection{Tissue Examination Process and Derived Waste in a Histopathology Laboratory}

The medical sector of histopathology connects the clinical practice and the basic science of medicine. The goal of the histopathology sector is to investigate the tissue changes and to identify potential diseases. Another goal is to analyze the likely underlying tissue changes that can affect a part or accompany a disease, and the appearance of medical symptoms. [8] The objective of histopathology is to perform biopsies on tissue fragments removed after surgeries. The biopsy samples are usually very small, from masses of $\mathrm{mg}$ to less than 1g. [9],[10],[11]. In normal surgeries, on the other hand, the amounts removed can vary from a few grams to kilograms.

During a histological examination, the examinee's body part is delivered to the laboratoryin a container soaked in a fixative material. The fixative material stops the autolysis of the tissue and preserves the structural stability of the cells. Typical fixative materials used in all HISTOLBs are aldehydes and particularlyformaldehyde. The pathologist examines the sample and selects the whole or a part of the tissue for further processing and examination. The typical medical consumablesused in the process are gloves, knife blade, cotton, cotton tissues, filter paper. Then, the sections of processed tissue are placed in a table tissue processor to carry out dehydration and refining of the cells, using ethanol and a mixture of three xylenes. The final stage of processing is the preparation of paraffin cubes that contain the tissue parts. Then paraffin cubes are cut into thin peels on a microtome and are placed on slide plates. The parts of the tissue will be painted with stains of hematoxylin and eosin. The histopathology medical staff examines, then, the final shape of the slide under a microscope.

Formaldehyde $\left(\mathrm{CH}_{2} \mathrm{O}\right)$ is typically used in HISTOLBs to preserve tissues. At room temperature, formaldehyde (FMLD) is a colorless gas with an irritating odor. Its code in the European Waste Catalogue is 180106 and is designated as a hazardous compound. Pure formaldehyde cannot be found in storesbut is sold as an aqueous solution at a $30-50 \%$ purity (by weight). It is highly reactive, it readily undergoes polymerization, it highly flammable, and can form explosive mixtures in the air. It decomposesat temperatures above $150{ }^{\circ} \mathrm{C}$. Based on laboratory studies, the inhalation of FMLD under conditions that induce cytotoxicity and sustained regenerative proliferation is considered to present a carcinogenic hazard to humans (WHO, 2002, European Commission, 2008). In HISTOLBs, the FMLD is separated from the tissue prior to analysis using a simple screen. FMLD alone is then disposed of as a separate liquid waste, without including tissue parts.

\section{Materials and Methods}

\subsection{Case Study and Sampling Period}

The study was conducted on three public and four private histopathological laboratories in the city of Thessaloniki, which is the 2nd largest city in Greece with a population of around 1,500,000 inhabitants. The selected laboratories were estimated to cover about $80-85 \%$ of the city's examinees that perform biopsy examination in the city's histopathology laboratories. Sampling period lasted a total of five months (September 2017 to January 2018). One 5dayweek per month was randomly selected and daily measurements were performed during that week. The sampling periods per laboratory are shown in detail in Table 1 . Thus, a total of 25 daily measurements were performed per laboratory over that 5-month period. Biopsy samples were weighed per examinee on the same day that the analysis took place in each laboratory. The total amount of waste collected over a day was assigned to the number of examinees for that specific day. Thus, all results were eventually expressed

in units of g/examinee. During statistical analysis, we used the weekly amounts of MW and the weekly number of examinees per laboratory to express the results in g/examinee. It is noted that the term "examinee" was preferred over the term "patient", since not all examinees carried a disease. The capacities of the seven HISTOLBs and the corresponding sampling periods are included in Table 1. 
Table 1: Characteristics of the seven histopathology laboratories and sampling weeks per laboratory.

\begin{tabular}{|c|c|c|c|}
\hline Code & Type of facility & $\begin{array}{l}\text { Approximate capacity } \\
\text { (examinees / month) }\end{array}$ & Sampling period \\
\hline Pub1 & $\begin{array}{c}\text { PUBLIC (DEPARTMENT OF A } \\
\text { PUBLIC HOSPITAL) }\end{array}$ & 600 & $\begin{array}{l}04 / 09 / 2017-08 / 09 / 2017, \\
09 / 10 / 2017-13 / 10 / 2017, \\
20 / 11 / 2017-24 / 11 / 2017 \\
27 / 12 / 2017-05 / 12 / 2017 \\
15 / 01 / 2018-19 / 01 / 2018\end{array}$ \\
\hline Pub2 & $\begin{array}{c}\text { PUBLIC (DEPARTMENT OF A } \\
\text { PUBLIC UNIVERSITY } \\
\text { HOSPITAL) }\end{array}$ & 300 & $\begin{array}{c}11 / 09 / 2017-15 / 09 / 2017 \\
02 / 10 / 2017-06 / 10 / 2017 \\
13 / 11 / 2017-17 / 11 / 2017 \\
8 / 12 / 2017-22 / 12 / 2017 \\
08 / 01 / 2018-12 / 01 / 2018\end{array}$ \\
\hline Pub3 & $\begin{array}{c}\text { PUBLIC (DEPARTMENT OF A } \\
\text { PUBLIC HOSPITAL) }\end{array}$ & 700 & $\begin{array}{c}18 / 09 / 2017-22 / 09 / 2017 \\
23 / 10 / 2017-27 / 10 / 2017 \\
06 / 11 / 2017-10 / 11 / 2017 \\
04 / 12 / 2017-08 / 12 / 2017 \\
29 / 01 / 2018-02 / 02 / 2018\end{array}$ \\
\hline Priv1 & PRIVATE & 800 & $\begin{array}{l}04 / 09 / 2017-08 / 09 / 2017 \\
16 / 10 / 2017-20 / 10 / 2017 \\
20 / 11 / 2017-24 / 11 / 2017 \\
11 / 12 / 2017-15 / 12 / 2017 \\
22 / 01 / 2018-26 / 01 / 2018\end{array}$ \\
\hline Priv2 & PRIVATE & 200 & $\begin{array}{c}18 / 09 / 2017-22 / 09 / 2017 \\
09 / 10 / 2017-13 / 10 / 2017 \\
27 / 11 / 2017-1 / 12 / 2017 \\
27 / 12 / 2017-05 / 12 / 2017 \\
15 / 01 / 2019-19 / 01 / 2019\end{array}$ \\
\hline Priv3 & PRIVATE & 250 & $\begin{array}{l}25 / 09 / 2017-29 / 09 / 2017 \\
16 / 10 / 2017-20 / 10 / 2017 \\
13 / 11 / 2017-17 / 11 / 2017 \\
04 / 12 / 2017-08 / 12 / 2017 \\
08 / 01 / 2018-12 / 01 / 2018\end{array}$ \\
\hline Priv4 & PRIVATE & 600 & $\begin{array}{c}11 / 09 / 2017-15 / 09 / 2017 \\
02 / 10 / 2017-06 / 10 / 2017 \\
06 / 11 / 2017-10 / 11 / 2017 \\
18 / 12 / 2017-22 / 12 / 2017 \\
22 / 01 / 2018-26 / 01 / 2018\end{array}$ \\
\hline
\end{tabular}

\subsection{Equipment Used in the Seven HISTOLBs}

The types and numbers of equipment used per laboratory is included in Table 2. This information is provided to allow a rough estimation of the toxic liquid waste generated due to the disposal of the reagents used by the equipment of each laboratory. It is clarified that no direct measurement of that fraction was made since this information was not available by any of the laboratories involved in the study. This amount does not include the formaldehyde that was placed in the container that preserved the tissue brought for analysis which was measured separately and with precision every sampling day.

Table 2 shows the number of reported equipmentpresent in all seven HISTOLBs used in this study. Apart from the histological examinations, liquid waste was generated by the tissue processing equipment and during the immunohistochemistryexamination. A total of sevensuch equipment wasrecorded in the three public hospitals and five equipment were present in the four private laboratories. This difference in the ratio can be justified by the fact that public hospitals have educational courses if they are joined with universities and have more medical staff. As a result of the above, more tissue processor equipmentare found per public hospital compared to the private facilities. 
Table 2: Number of total equipment and reagent containers for the three public and four private laboratories used in the study.

\begin{tabular}{|l|l|l|l|l|l|l|l|}
\hline & $(1)$ & $(2)$ & $(3)$ & $(4)$ & $(5)$ & $(6)$ & $(7)$ \\
\hline Public & 7 & 10 & 30 & 9 & 2 & 6 & 1 \\
\hline Private & 5 & 10 & 10 & 27 & 2 & 2 & 3 \\
\hline
\end{tabular}

Number of : (1) tissue processing equipment; (2): $1500 \mathrm{~mL}$ liquid solution containers; (3): $2200 \mathrm{~mL}$ liquid solution containers; (4): $5000 \mathrm{~mL}$ liquid solution containers; (5): $1500 \mathrm{~mL}$ wax containers; (6): $1800 \mathrm{~mL}$ wax containers; (7): $5000 \mathrm{~mL}$ wax containers.

In total, there were 12 tissue processorsin total in the 7 HISTOLBs and there were three different types of tissue processing techniques applied by those tissue processors that affect the generation of waste. For example, some of these models come in direct contact with the tissue casings, and some others just infuse the tissue casings with the liquid solution. In the first model type, the liquid solution is added to cover all the quantity losses from the processing activity. As soon as the principal liquid solution becomes contaminated, it is replaced.On the other hand, the second model type constantly provides clean liquid solutions. Therefore, only when the amount of liquid solutions is reduced drastically and is no longer usable, the machine automatically informs the user to replace the empty containers with a new one. The positive aspect of the 2 nd model is that the remaining liquid solution is pure and can be reused for other laboratory functions. Half of the private laboratories had a recycling apparatus to recycle ethanol and xylenes. The recycled processed liquid solution cannot replace original grade reagents into the tissue processing analyzer; however,it can be used in reprocessing machines to reduce cost.

Also, many HISTOLBs (both in the public and private sectors) adopted used(instead of new) cutting blades in the microtome machines, for the primary processing of samples, as part of their waste reuse policy.

According to Table 2, it was estimated that roughly 50-80 L of combined liquid wasted chemicals,(formaldehyde, ethanol, xylene and waste water) is generated by the laboratories per month due to replacing equipment reagents and the disposal of the old ones. This amount is not included in the waste fractions reported below, since they were not measured with precision.

\subsection{Practices of Waste Disposal in the Seven HISTOLBs}

The source separation of MW in the involved HISTOLBs followsthe categorization of hazardous medical waste of the Greek legislationmentioned before. The source separation within each laboratory is done by medical and paramedical staff at the source. Each type of MW is placed in separate containers according to their quality characteristics and method of treatment. In some cases, the possibilities for recycling re-use or recovery are taken into account.

Separated waste is placed in the appropriate containers with a designated color (e.g. yellow, red) and characteristics, depending on their composition and the treatment that follows (e.g. sterilization, incineration). In all 7 laboratories under study, there were three types of containers to dispose of MW.

Each container (or plastic bag) corresponds to the infectious, mixed hazardous and toxic waste fractions, respectively. In the labs under study, no separate container existed for the disposal of urban type medical waste that, in some cases, was disposed of, erroneously, together with the infectious waste. In this study, we separately weighed the infectious waste groups, prior to their placement in the bag, and weighed them separatelyin order to have a precise estimation of the solely infectious part. At the end of the day, the whole infectious waste bag was again weighed. Thus, an indirect estimation of the urban waste disposed of into the infectious waste bag was feasible.

The three types of MW separated and weighed in each laboratory were:

Infectious waste

The infectious waste comprises four main categories. Each category was weighed separately in this study. The four categories are:

a) Sharps, namely the cutting razors, which are used to cutthe tissue.

b) Single use latex gloves, which are used by the medical staff.

c) Cotton used to clean the tissue or the working bench from body liquids and filter paper.

d) Empty plastic containersthat transport the tissue and the formaldehyde into the laboratory. The formaldehyde is normally drained and disposed of separately as toxic waste (see below) and the spent tissue is also disposed of separately as mixed hazardous waste. The empty container that remains after the disposal of the tissue and the formaldehyde is classified and treated as infectious waste.

All infectious waste is placed in yellow bags placedin 5-10 L bins. After temporary storage within the lab, INF waste is transported to a sterilization facility. 


\section{Mixed hazardous waste (infectious and toxic)}

The mixed hazardous waste (MXW) (i.e. infectious and toxic) comprises solely of the remaining tissue after its separation from the formaldehyde. The spent tissue is weighed and classified as mixed hazardous waste. The MXH is placed intoredbags placed in $10 \mathrm{~L}$ cardboard boxes. According to the Greek legislation, the residual tissue must be stored within the HISTOLB for a period of 30 days, in case an extra processing is necessary after first analysis. MXW is then transported for incineration.

Toxic waste

The formaldehyde is the only toxic (liquid) waste generated by the laboratories. Formaldehyde is disposed of into $30 \mathrm{~L}$ containers prior to itsdelivery to MW incineration facilities, as required by the legislation. The containers are erosion-resistant and are stored in the laboratory until they are two thirds full. Then, they are transported to a MW incineration facility together with the MHW.

Urban type waste

The relatively small amounts of urban type waste (plastic water bottles, office paper, old newsprint, magazines, food waste and its packaging) generated by the HISTOLBs were placed in the infectious waste bag in six from the seven laboratories. In this study, the urban waste was not directly weighed. However, it was indirectly quantified from the difference of the sum of the weight of the four infectious waste categories (that were each weighed separately) from the total weight of the "infectious" waste bag that was again weighed at the end of the day.

A precision scale (KERN EWJ laboratory balance, with resolution of $0.01 \mathrm{~g}$ )was used to weigh all types of MW before and after the processing of the tissue in collaboration with the medical pathologist in charge. Statistical analysis and graphing of the results was done using a Minitab® v17 and Excel.

\section{Results and Discussion}

\subsection{Generation Rates and Composition of MW}

Figure 1 and Table 3present the average amounts and composition of the total MW (hazardous and non-hazardous fractions) generated by the public and private HISTOLBs. Figure 1 reveals that the urban type MW represent only a minor fraction of the total MW being only $2-4 \%$ of the total weight. Thus, the remaining fraction is the hazardous waste. According to Figure 1, the majority(around 56\%) of the total MWconsists of toxic wastein both the public and the private laboratories. This toxic waste is practically the spent formaldehyde that is disposed of in large quantities from all HISTOLBs. Mixed hazardous waste comprises between $24 \%$ to $28 \%$ of the total MWweight. Finally, infectious waste comprisesaround $15 \%$ of the total MWgenerated. This composition of MW from the HISTOLBs differs significantly from the typical composition of MW disposed of from general hospitals in which infectious waste usually prevails $>50 \%$ by weight) and toxic waste is present in rather small quantitiesbeing below $10 \%$ by weight([3], [12], [13]).

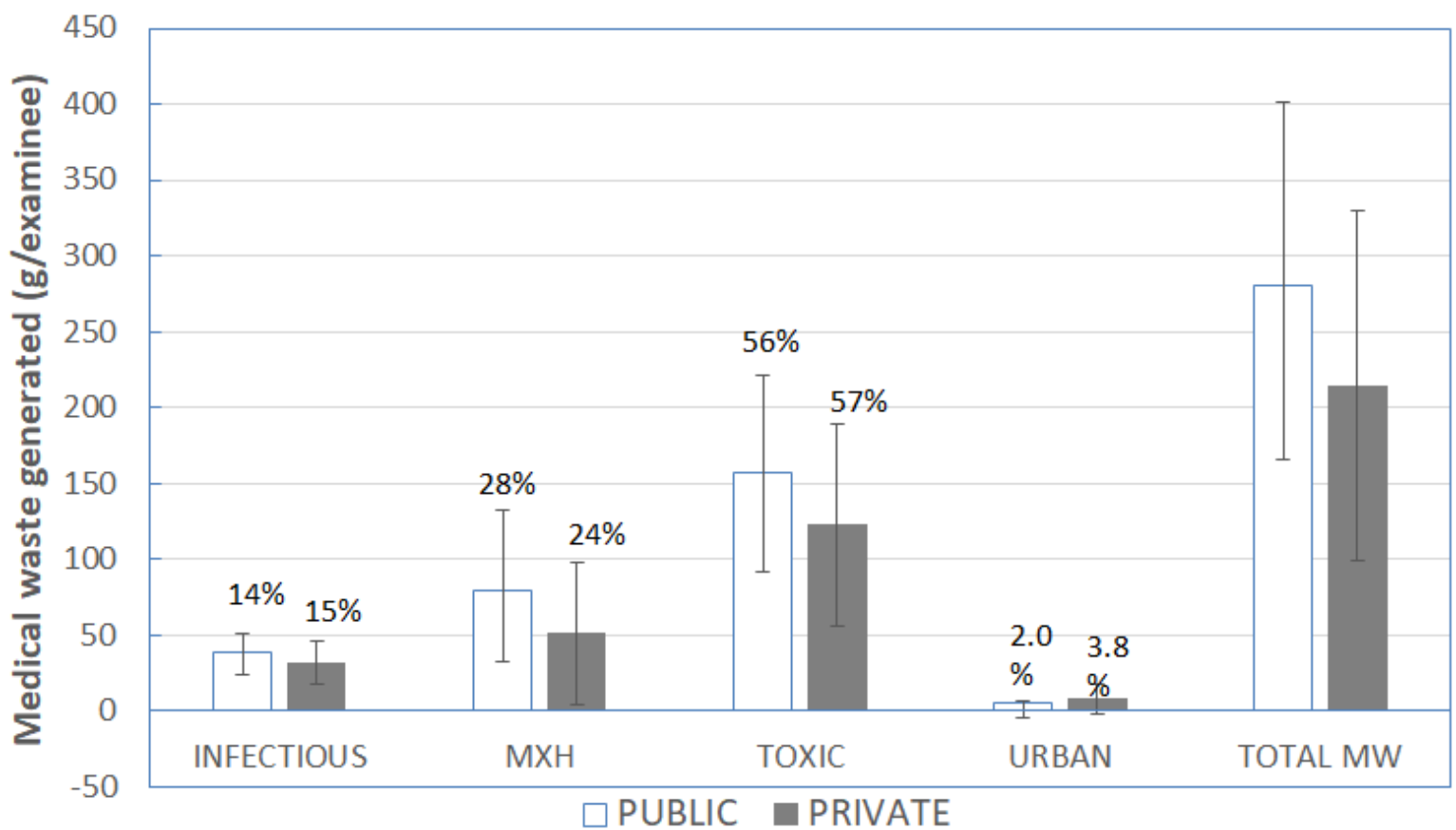

Fig. 1: Average amounts of medical waste generated per type of histopathology laboratory. 
Errors bars are standard deviations based on $n=15$ for the public laboratories and $n=20$ for the private laboratories). The sum of "Infectious", "MXH", "Toxic" and "URBAN" equals the "Total MW". Percentages shown represent the amount of the corresponding type of waste on a per total MW basis.

The amount of MW generated by each laboratory in a period of time is a function of the amounts of examinees examined by the same laboratory over the same period. This is apparent and has been also noticed in clinical microbiology laboratories ([2]) as well as in large hospitals ([13]). This positive correlation is clearly revealed in Figure 2 and suggests that as the number of examinees increases, the amount of medical waste usually increases too. According to Figure 2, this positive correlation is stronger in the case of private laboratories than the public laboratories. This might be attributed to the fact that a more careful management of waste is practiced in the private HISTOLBs compared to the public ones. Figure 2 is useful only to interpret the correlations achieved rather than to conclude on the unit generations rates (g/examinee) per type of hospital. For example, the negative intercept noticed for the regression line of the private hospitals has no physical meaning and is a mere statistical technique to improve the accuracy of the linear correlation. The poor correlation between number of examinees and waste amount in the public laboratories can be also attributed to the fact that one examinee might have had more than one examination (i.e. more than one tissue samples) done in the same laboratory. For example, in one laboratory during our sampling period, twelve (12) samples had been registered to one examinee. Thus, the number of examinations, and not of the examinees, could have been a better predictor of MW amounts than the examinees. The number of examinations was not recorded in our work.

Based on Table 3, the total MW generated by the public and private HISTOLBs ranged from approximately 230 to 340 g/examinee, and from 190 to 240 g/examinee, respectively. According to Table 3, the amounts of total MW (in g/examinee) were statistically similar among the 5 months in both the public and private sector. However, in January 2018 only, the total MW generated by all three public HISTOLBs was slightly increased compared to the previous months. Yet, such seasonal variations are normal for health-care facilities. According to the same table, the number of examinees in the public laboratories is higher than the examinees visiting the private laboratories. This preference towards the public sector can be attributed merely to financial motives, since examinations in public health-care facilities are usually covered by social security in Greece. According to Table 3, approximately 400 and 360 examinees visit the public and private HISTOLBs, respectively, per month in the area under study.

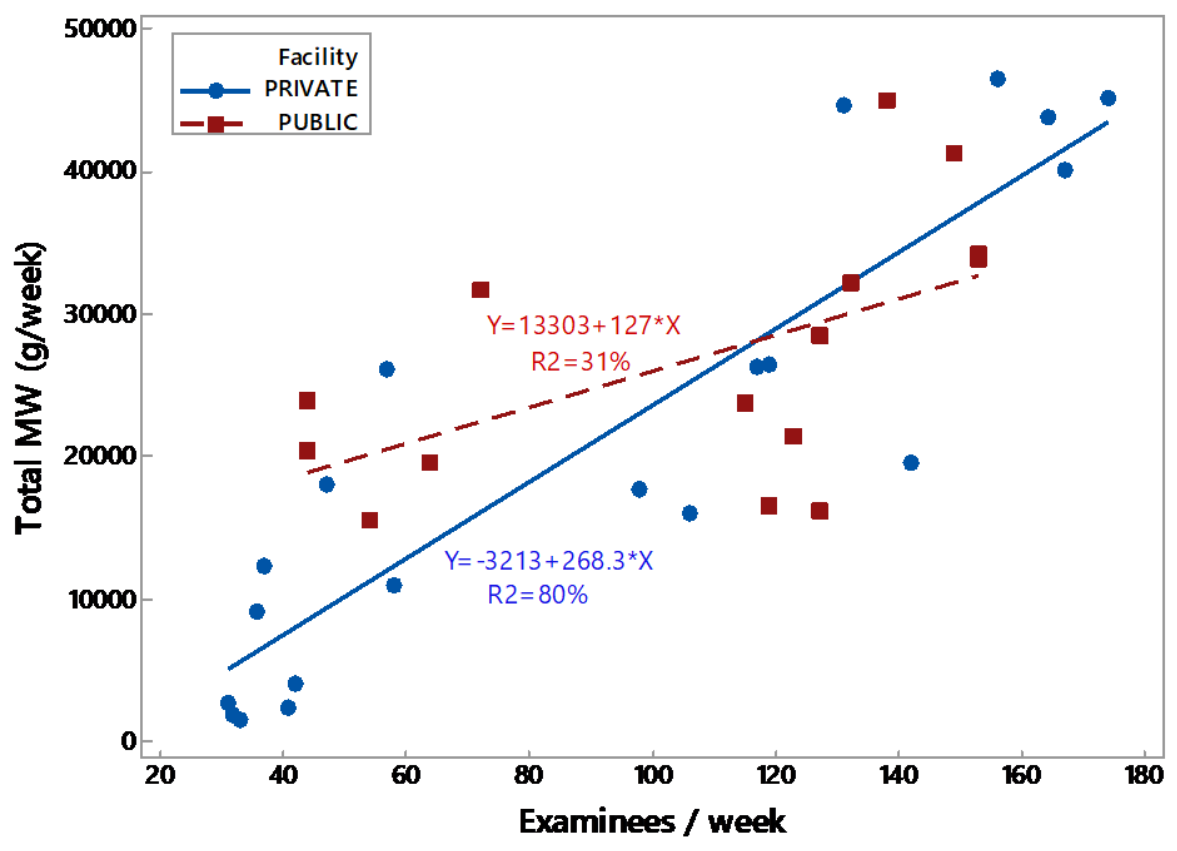

Fig. 2: Correlation of weekly number of examinees with the weekly amount of total MW generated by each laboratory. 
Table 3: Amounts of total medical waste (hazardous and non-hazardous) generated in the histopathology laboratories per sampling month.

\begin{tabular}{|l|c|l|c|c|c|}
\hline TYPE OF WASTE & SEPTEMBER & OCTOBER & NOVEMBER & DECEMBER & JANUARY \\
\hline PUBLIC SECTOR & & & & & \\
\hline Examinees per week & $113 \pm 45$ & $107 \pm 50$ & $116 \pm 40$ & $101 \pm 50$ & $100 \pm 50$ \\
\hline Total MW (g/examinee) & $234 \pm 66.5$ & $240 \pm 43.7$ & $314 \pm 113$ & $279 \pm 171$ & $337 \pm 203$ \\
\hline PRIVATE SECTOR & & & & & \\
& & & & & \\
\hline Examinees per week & $85 \pm 48$ & $93 \pm 59$ & $99 \pm 58$ & $86 \pm 64$ & $85 \pm 67$ \\
\hline Total MW (g/examinee) & $203 \pm 117$ & $243 \pm 119$ & $238 \pm 177$ & $193 \pm 122$ & $195 \pm 79.5$ \\
\hline
\end{tabular}

Means \pm STD ( $n=3$ for public laboratories and $n=4$ for private laboratories); All monthly means were statistically similar pertype of facility based on ANOVA (Tukey's test) at $p<0.05$.

Figure 3 illustrates the distribution of the amounts of the three main categories of the hazardous medical waste fraction that is generated per month. The large variance observed within each of the two main groups (public, private) results in the monthly mean valuesto be statistically similar among all 5 months. This internal large variance within each group is attributed to the large variability among the MW amounts generated by each of the seven laboratories.

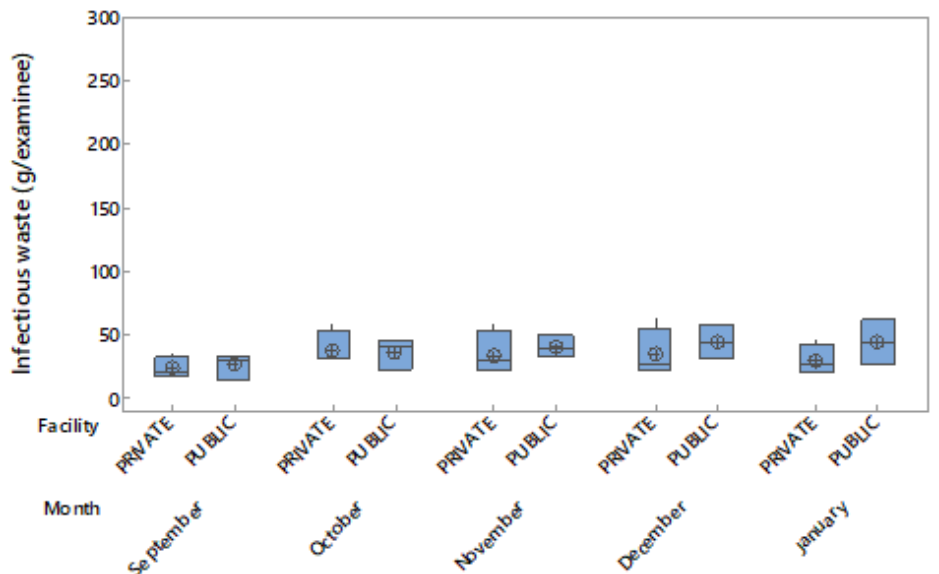

a)

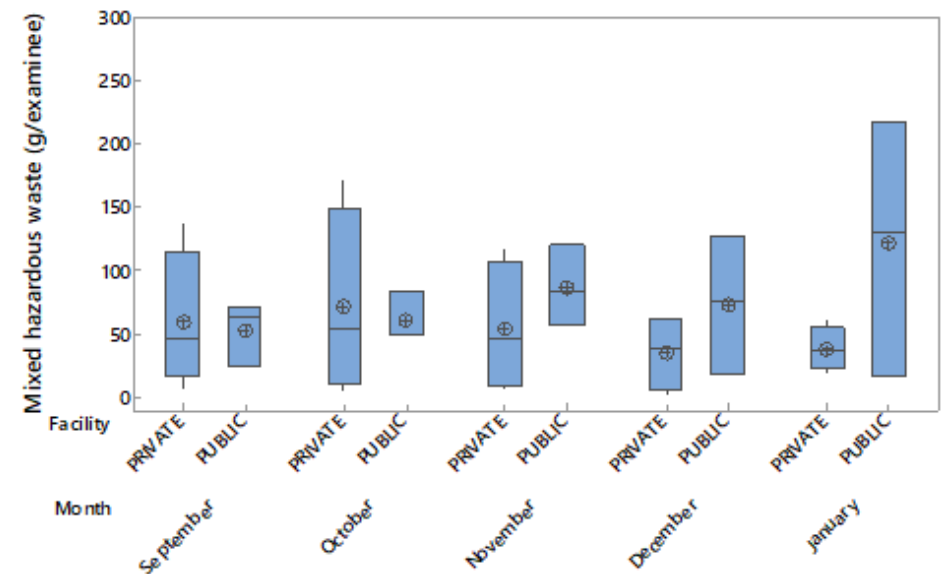

b)

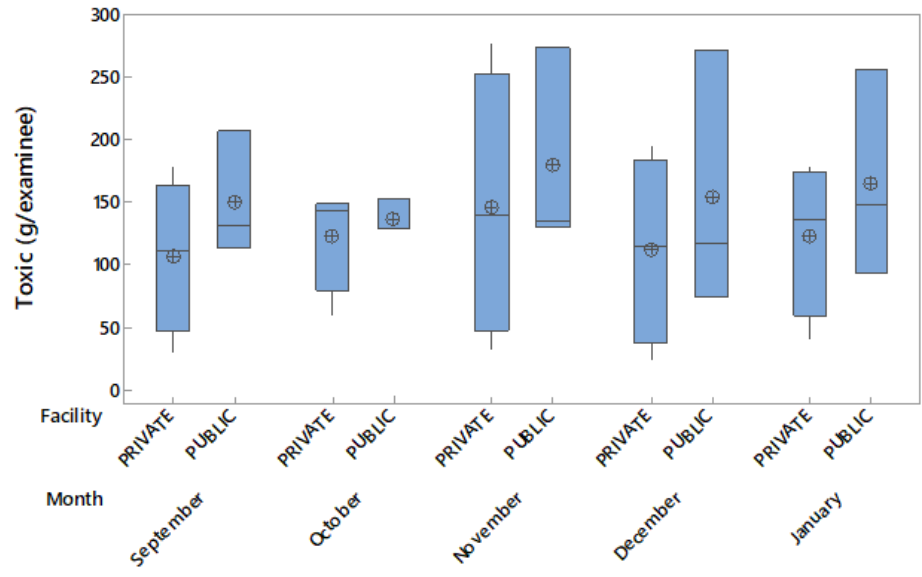

(c)

Fig. 3: Variability of MW waste generation rates per sampling month in both types of HISTOLABs (a: infectious, b: mixed hazardous, c: toxic).

\subsection{Statistical Differences among Laboratories}

Figure 4 reveals that there were actually statistically significant differences among the means of the individual laboratories used in the study, even for the ones that belonged to the same group (i.e. public, private). 
For example, the PUB2 (public) hospital had statistically higher generation rates (408 g/examinee) compared to the other two public laboratories. In addition, the PRIV2 (private) laboratory had a characteristically lower generation rate, close to around $70 \mathrm{~g} / \mathrm{examinee}$, than the other private laboratories (which had means that ranged from private). This variability is seen in both the total MW as well as the in all fractions of MW (only the toxic waste is shown in Figure 4). The trend in the differences was similar to all hazardous medical waste fractions. This variation might be attributed to different practices within the laboratory as well as waste reuse practices. Due to those large variances observed among the individual HISTOLBs of our study, no statistical differences between the two types of facilities (public, private) were found (see Table 4).

Table 4: Statistical differences of the MW generation rates between public and private laboratories.

\begin{tabular}{|c|c|c|c|c|c|}
\hline $\begin{array}{c}\text { Type of } \\
\text { HISTOLAB }\end{array}$ & $\begin{array}{c}\text { Infectious } \\
\text { waste }\end{array}$ & $\begin{array}{c}\text { Mixed hazardous } \\
\text { waste }\end{array}$ & Toxic waste & Urban waste & Total MW \\
\hline Public & $38.2^{\mathrm{A}} \pm 12.9$ & $79.0^{\mathrm{A}} \pm 53.3$ & $157.7^{\mathrm{A}} \pm 64.1$ & $5.7^{\mathrm{A}} \pm 1.4$ & $280.6^{\mathrm{A}} \pm 120.5$ \\
\hline Private & $32.0^{\mathrm{A}} \pm 14.4$ & $51.4^{\mathrm{A}} \pm 46.9$ & $122.7^{\mathrm{A}} \pm 66.3$ & $8.1^{\mathrm{A}} \pm 9.9$ & $214.3^{\mathrm{A}} \pm 114.9$ \\
\hline
\end{tabular}

Means \pm SD; Means that share the same letter are statistically similar at $\mathrm{p}<0.05$.

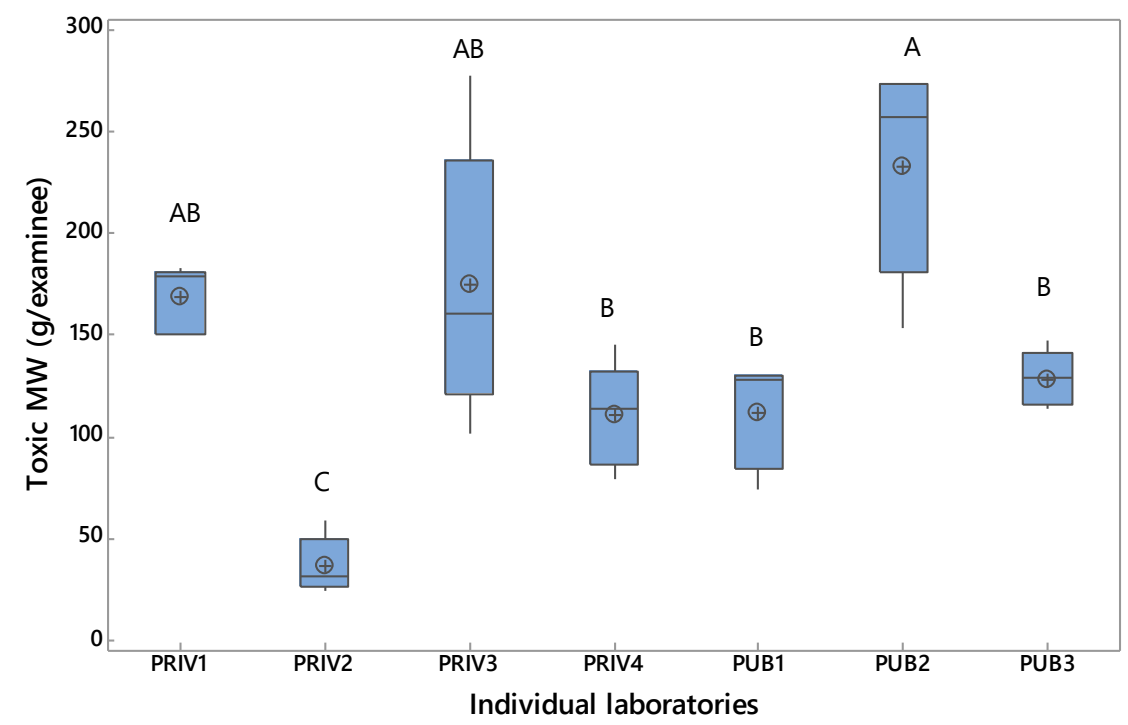

(a)

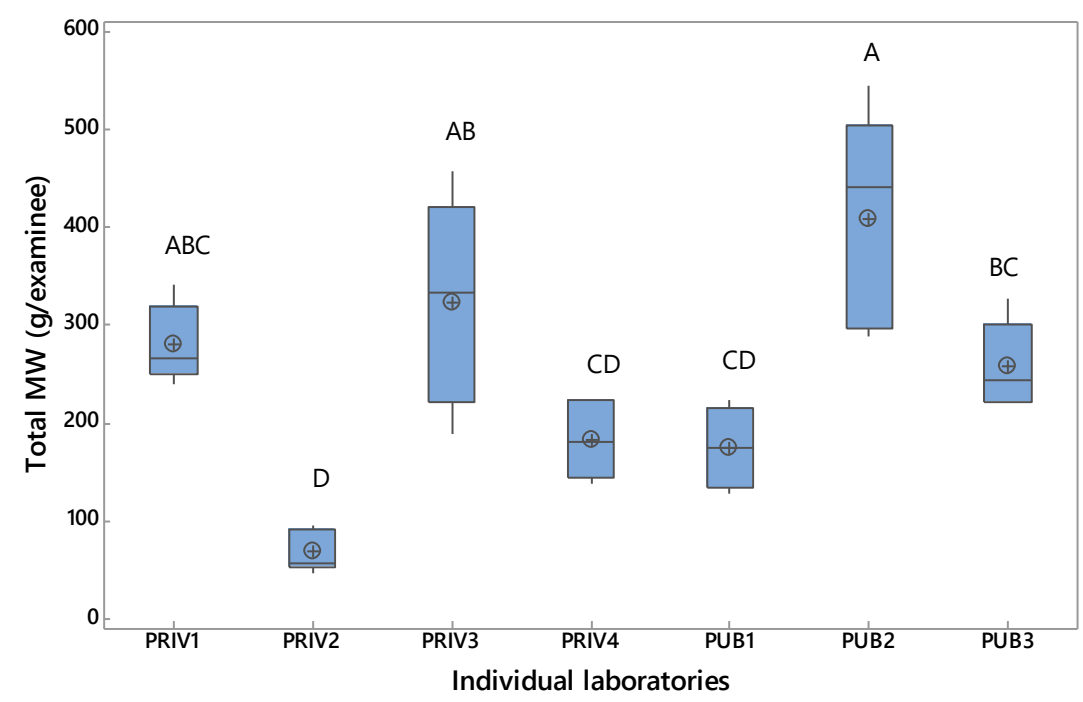

(b)

Fig. 4: MW (toxic: a, total: b) generated per individual laboratory used in the study (same letters indicate statistically equal means at $\mathrm{p}<0.05)$. 
Despite the statistical similarity found among all means of Table 4, one can observe that the public labs generatedhigher amounts of both mixed hazardous and toxic waste than the private ones. This might be attributed to the fact that private labs might employ waste reuse and recycling attitudes to a higher degree compared to the public laboratories, for reasons of financial viability.

\subsection{Categories of Infectious Waste}

The grouping of infectious waste is depicted in Figure 5.

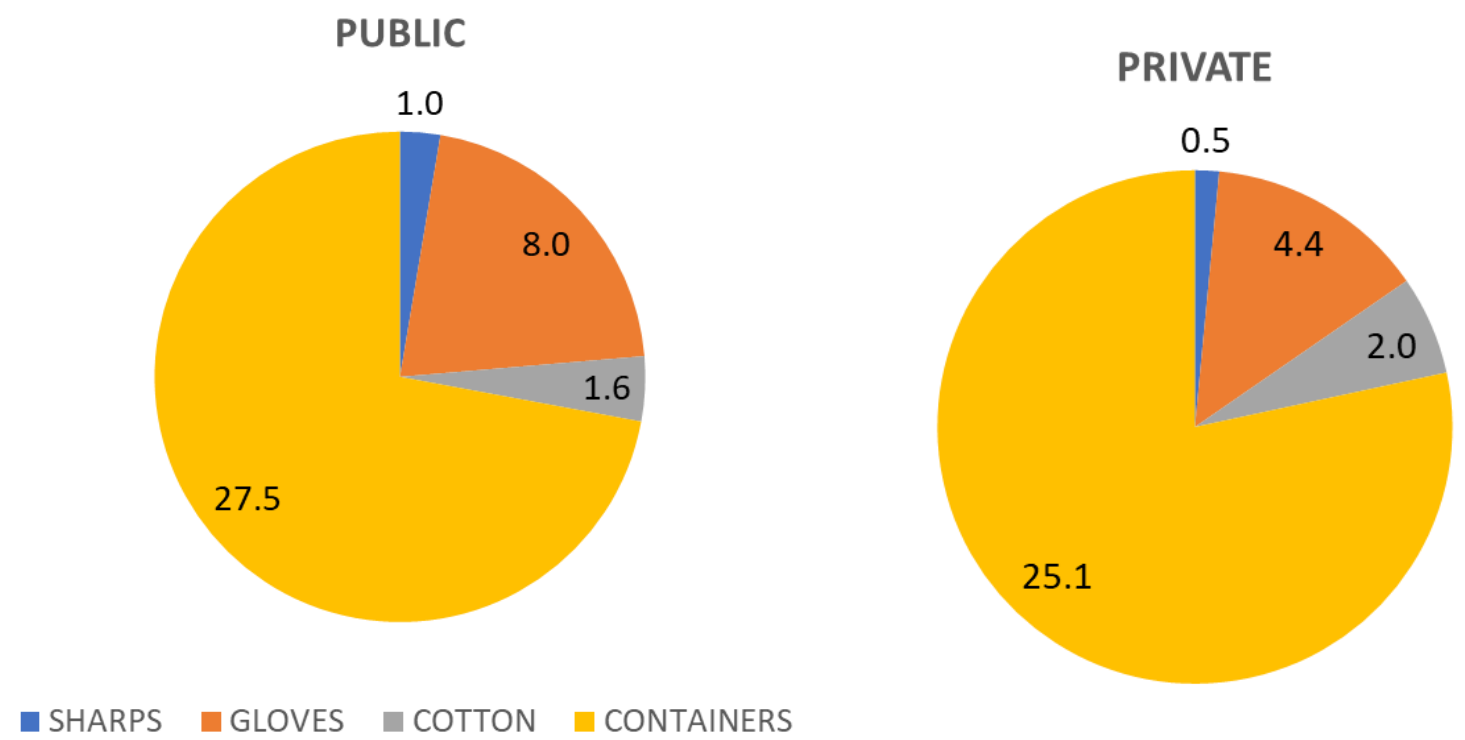

Fig. 5: Distribution of infectious waste sub-components in the public and private HISTOLBs (amounts are in g/examinee).

According to Figure 5, the percentages of the infectious waste sub-components are similar between the public and private labs. Apparently, the plastic containers, which are disposed of as infectious waste, is the major infectious waste component which constitutes around $72 \%$ to $78 \%$ of the total infectious waste weight. Gloves is the component with next highest quantity in the infectious waste stream in both types of laboratories.

\subsection{Suggestions to Improve Waste Management in HISTOLBs}

Infectious waste should be separated more carefully so that do not contain urban type solid waste, as is erroneously practiced currently by most of the laboratories. The acquisition of modern tissue processing equipment can aid in the reduction of liquid wastewater.

\section{Conclusions}

Conclusions of this work are:

1. Fifty-seven percent (57\%) of the total MW generated in both the public and private laboratories were toxic waste (TXW), namely the liquid formaldehyde that is used to preserve the tissue.

2. The mixed hazardous waste (MHW) comprised $28 \%$ and $24 \%$, respectively, of the total MW, in the public and private facilities, respectively. The infectious waste constituted around 15\% of the total MW generated in both types of facilities.

3. Urban type waste weighed always less than $4 \%$ of the total MW weight.

4. The total MW generated in the public and private laboratories were $281 \pm 121$ and $214 \pm 115 \mathrm{~g}$ /examinee, respectively, whilst no statistical differences were found between the MW generation rates of the public and private laboratories.

5. A large variance in the MW generation rates among individual laboratories that belonged to the same category was observed. The range of the total MW generation rate measured in the public HISTOLB was 174 to 259 g/examinee, whilst the MW generation rate range measured in the private HISTOLBs was 69 to $323 \mathrm{~g} /$ examinee.

6. The dominant fraction of the infectious waste was the plastic containers that contained the tissue samples; this was around $75 \%$ of the total infectious waste, followed by the latex gloves (around 17\% of the infectious waste). 
7. No seasonal differences of the MW generation rates were observed among the five months of the study.

\section{Acknowledgements}

The authors wish to warmly acknowledge the managers of all departments and private laboratories involved in the study. This work would not have been possible without their sincere support and cooperation.

\section{References}

[1] World Health Organization. (2018, 3 Apr). Health-care waste. [Online]. Available: http://www.who.int/mediacentre/factsheets/fs253/en/

[2] D. Komilis, N. Makroleivaditis, and E. Nikolakopoulou, "Generation and composition of medical wastes from private medical microbiology laboratories," Waste management, vol. 61, pp. 539-546, 2017.

[3] E. Voudrias and A. Graikos, "Infectious medical waste management system at the regional level," Journal of Hazardous, Toxic, and Radioactive Waste, vol. 18, no. 4, p. 04014020, 2014.

[4] I. A. Al-Khatib, I. Abu Fkhidah, J. I. Khatib, and S. Kontogianni, "Implementation of a multi-variable regression analysis in the assessment of the generation rate and composition of hospital solid waste for the design of a sustainable management system in developing countries," Waste Management \& Research, vol. 34, no. 3, pp. 225-234, 2016.

[5] M. A. Patwary, W. T. O'Hare, and M. H. Sarker, "Assessment of occupational and environmental safety associated with medical waste disposal in developing countries: a qualitative approach," Safety science, vol. 49, no. 8-9, pp. 1200-1207, 2011.

[6] E. Tesfahun, A. Kumie, W. Legesse, H. Kloos, and A. Beyene, "Assessment of composition and generation rate of healthcare wastes in selected public and private hospitals of Ethiopia," Waste Management \& Research, vol. 32, no. 3, pp. 215-220, 2014.

[7] D. Eleyan, I. A. Al-Khatib, and J. Garfield, "System dynamics model for hospital waste characterization and generation in developing countries," Waste Management \& Research, vol. 31, no. 10, pp. 986-995, 2013.

[8] V. Kumar, A. Abbas, N. Fausto, and R. Mitchell, "Chapter 1: Cell injury, cell death, and adaptations," Kumar V, Abbas AK, Fausto N, Mitchell R. Robbins basic pathology. 8th edition, Elsevier-Saunders, Philadelphia, pp. 1317, 2007.

[9] M. Boshart, L. Gissmann, H. Ikenberg, A. Kleinheinz, W. Scheurlen, and H. z. Hausen, "A new type of papillomavirus DNA, its presence in genital cancer biopsies and in cell lines derived from cervical cancer," The EMBO journal, vol. 3, no. 5, pp. 1151-1157, 1984

[10] R. A. Shanely, K. A. Zwetsloot, N. T. Triplett, M. P. Meaney, G. E. Farris, and D. C. Nieman, "Human skeletal muscle biopsy procedures using the modified Bergström technique," Journal of visualized experiments: JoVE, no. $91,2014$.

[11] E. H. Kossoff et al., "Optimal clinical management of children receiving the ketogenic diet: recommendations of the International Ketogenic Diet Study Group," Epilepsia, vol. 50, no. 2, pp. 304-317, 2009.

[12] M. Tsakona, E. Anagnostopoulou, and E. Gidarakos, "Hospital waste management and toxicity evaluation: a case study," Waste management, vol. 27, no. 7, pp. 912-920, 2007.

[13] D. Komilis, N. Katsafaros, and P. Vassilopoulos, "Hazardous medical waste generation in Greece: case studies from medical facilities in Attica and from a small insular hospital," Waste Management \& Research, vol. 29, no. 8, pp. 807-814, 2011. 